\title{
CANIBALISMO, MASACRES Y ESCLAVISMO EN LAS CAMPAÑAS CORTESIANAS: LA PREPARACIÓN DEL ASEDIO DE MÉXICO-TENOCHTITLAN EN 1520-1521
}

\author{
Cannibalism, massacres and slavery \\ in Cortés' campaigns: preparation of the siege \\ of Tenochtitlan in 1520-1521
}

\author{
Antonio Espino López \\ Universidad Autónoma de Barcelona, España
}

\begin{abstract}
Resumen: En este trabajo, mi interés principal han sido los diversos aspectos (canibalismo, masacres y esclavismo) que subyacen en las campañas relativamente menos conocidas emprendidas por Hernán Cortés y sus hombres, incluidos entre estos últimos los aliados aborígenes, entre julio y agosto de 1520 y mayo de 1521, para debilitar al Imperio mexica antes del asalto final a la gran urbe México-Tenochtitlan entre mayo y agosto de 1521. Las principales fuentes utilizadas han sido una serie de crónicas, no menos de once, y otros testimonios de la época, además de bibliografía moderna.
\end{abstract}

Palabras clave: Hernán Cortés, conquista de México, canibalismo, masacres, esclavismo, terror.

Abstract: In this work, my intention has been to examine various underlying aspects (cannibalism, massacres, and slavery) of the relatively lesser-known campaigns undertaken by Hernán Cortés and his men, including the allied indigenous peoples, between July and August 1520 and May 1521, to weaken the Mexican Empire before their final assault on the great city of Tenochtitlan between May and August 1521. The main sources used have been a series of chronicles from the period, no less than eleven, as well as modern literature and other testimonies of the time.

Keywords: Hernán Cortés, conquest of Mexico, cannibalism, massacres, slavery, terror. 


\section{Introducción}

Sin duda, la bibliografía acerca de la conquista de México por Hernán Cortés y su hueste es abrumadora. ${ }^{1} \mathrm{Y}$, con todo, nuevas relecturas de las crónicas clásicas, así como las más recientes aportaciones sobre diversas cuestiones concernientes al funcionamiento interno del Imperio mexica en toda su extensión, ${ }^{2}$ nos permitirán abordar algunos aspectos que, a mi juicio, no siempre son analizados con la adecuada perspectiva. Siendo la cortesiana una campaña harto conocida en toda su extensión cronológica, considero que las operaciones efectuadas entre la llegada a Tlaxcala después de la Noche Triste, en julio de 1520, y el inicio del asedio de la gran urbe mexica, a fines de mayo de 1521, conforman el período historiográficamente menos destacado de tan terrible epopeya, con diversos factores que merecería la pena recuperar para volver a repensarlos. Me centraré en tres aspectos: el canibalismo entre las filas cortesianas, las masacres promovidas (más allá de la de Cholula ${ }^{3}$ o de la perpetrada por Pedro de Alvarado en el Templo Mayor en el mes de tóxcatl) y la esclavitud de los derrotados o botín alternativo en aquella cruenta guerra. En mi opinión, son los tres aspectos más destacables de aquellas campañas parciales dentro del conjunto de la magna operación que conduciría a la conquista de MéxicoTenochtitlan. Y están interrelacionados, de ahí mi interés en su análisis conjunto en estas páginas.

\section{Canibalismo}

Con respecto al universo mexica, de manera tradicional se había pensado que la forma usual de obtener prisioneros para ser sacrificados era a través de un tipo de guerra ritualizada, o xochiyaóyotl, que se pactaba previamente entre los señores de diversos pueblos: las guerras floridas (Declercq, 2018: 197). Es conocida la afirmación del antropólogo Michael Harner de que los mexicas sacrificaban a un gran número de personas para poder canibalizarlas (ya que el imperio a fines del siglo xv se encontraba en plena crisis alimentaria), pero también como forma de equilibrar el sistema social y económico. Así, se refirió a la existencia de un «imperio caníbal», una hipótesis que fue rebatida un año después de ser establecida, en 1977, por Barbara Price. En cuanto a la antropofagia ritual mexica, sin duda existió, pero reservada a la clase privilegiada y, dentro de la misma, a la alta oficialidad militar. Esa ventaja gastronómica permitiría la supervivencia en un contexto de escasez de proteínas y haría, además, que se generase una «maquinaria bélica agresiva» (Harner, citado en Declercq, 2018: 70).

1. Martínez (1992); Thomas (1994); Graulich (1994); Grunberg (1995); Miralles (2004); Levy (2010); Mira Caballos (2010).

2. Bueno Bravo (2007); Cervera Obregón (2007); Aimi (2009); Hassig (2012; 2016); Martínez Martínez (2013); Martínez Martínez y Mayer (2016); Declercq (2018).

3. Sobre la masacre de Cholula, véanse Medin (2009: 210-217); Clendinnen (1991: 74); Martínez (1992: 228-238); Miralles (2004: 141-145); Thomas (1994: 295 y ss.); Grunberg (1995: 76 y ss.). 
Los informantes de fray Bernardino de Sahagún afirmaban que se distribuía el cuerpo del prisionero sacrificado siguiendo determinadas pautas de reparto si los captores habían sido varios. Además, los trofeos de guerra, como el corte de cabezas del enemigo (Gracia Alonso, 2017: 189-202), eran apreciados por el prestigio que otorgaban a los guerreros. En el caso mexica destaca la confección de largos muros a base de cráneos de guerreros enemigos, el tzompantli, que luego se expondría en la plaza central de Tenochtitlan y otros lugares. Con el tiempo, estos muros serían adornados también con cabezas de castellanos e, incluso, de sus cabellos (Cervera Obregón, 2011: 162-167). Por ello, cabe decir, siguiendo a Stan Declercq, quien se inspira en esta ocasión en los trabajos de M. Sahlins, que en el modelo mexica:

[...] nunca había canibalismo culinario. La víctima se asimila al dios y al sacrificante, y el consumo de la carne solamente tiene sentido por su carácter sagrado. Así, cautivos y esclavos eran divinizados. A través del consumo de la carne de las víctimas, se establece una comunión con los dioses. Al mismo tiempo, la fuerza divina se incorpora en los comensales (Declercq, 2018: 75). ${ }^{4}$

Pero lo cierto es que, en sociedades menos avanzadas, ${ }^{5}$ como los chichimecas, parece haber pruebas de ingesta de enemigos sin carácter ritual, sino plenamente dietético. Por otro lado, cabe preguntarse si cuando se produjeron sacrificios de castellanos su ingesta era ritual, a la manera de Sahlins, o si representaba una manera de vengarse y de castigarlos. $Y$ asimismo surge la pregunta de si, en el transcurso del sitio de México-Tenochtitlan, en unas condiciones terribles, la ingesta de los cuerpos de los vencidos podría constituir una manera de alimentarse fuera de todo tipo de consideración ritual. Estas cuestiones, planteadas por Declercq a partir de trabajos de Michel Graulich y Yolotl González Torres, demuestran la amplitud del debate. Y, con todo, lo más interesante sería la gestión, como se verá, que hizo Cortés de esta problemática cuando tuvo que permitir a sus aliados aborígenes semejantes prácticas (Declercq, 2018: 76-79).

En el caso de los tarascos, por analizar otras actitudes fuera del mundo mexica, los prisioneros jóvenes, hombres y mujeres, solían ser llevados de retorno a Michoacán sin demasiados problemas para su transporte, en cambio otros segmentos de la población eran destinados al canibalismo: «los viejos y viejas y los niños de cuna y los heridos, sacrificaban antes que se partiesen en los términos de sus enemigos, y cocían aquellas carnes y comíanselas» (Alcalá, 2008: 199). Sea como fuere, tampoco se puede olvidar que, en la cultura popular, por así decirlo, se ha extendido la idea de que las mesoamericanas eran unas sociedades belicosas, crueles y despiadadas fuera de medida. Ruvalcaba Mercado nos lo recuerda citando a Sophie Coe, para quien existe un viejo cliché según el cual «los aztecas eran unos militaristas sedientos de sangre, de-

4. También niega el canibalismo dietético Ruvalcaba Mercado (2018: 125 y ss.).

5. Para una crítica de la visión de los chichimecas como bárbaros, o más primitivos, en contraposición a los toltecas, máxima expresión de lo civilizado en aquel mundo, véase Navarrete (2011: 45). 
jándolo como una sobresimplificación ridícula, producto de la autojustificación de los europeos que ha sobrevivido a causa de ese rasgo sombrío que nubla nuestro pensamiento" (Ruvalcaba Mercado, 2018: 125).

Bernal Díaz del Castillo no tuvo reparos en señalar la presencia de la antropofagia tanto entre sus aliados totonacas como entre los tlaxcaltecas, al tiempo que aseveraba que al gran tlatoani Moctezuma II se le presentaban diversos platos de carne, entre ellas la humana - «Oí decir que le solían guisar carnes de muchachos de poca edad»-. Y el autor de Medina del Campo criticaría no solo la religión mexica con sus sacrificios, sino también ciertas costumbres totonacas, comunes a otros aborígenes, como la sodomía y la ingesta del cuerpo de los semejantes, que debería erradicarse - «Y cada día sacrificaban delante de nosotros tres o cuatro o cinco indios [...] y cortábanles las piernas y los brazos y muslos, y los comían como vaca que se trae de las carnecerías en nuestra tierra»-. En Tlaxcala, obligarían a que fuesen soltados aquellos indios que, en sus prisiones, aguardaban para ser sacrificados y devorados. De alguna forma, Díaz del Castillo subraya de esta forma la faceta más «bárbara» y cruel de los habitantes de aquellas tierras. Y habría incluso una justificación para el triunfo de la conquista, que sería la erradicación de manera definitiva del canibalismo. Si la presencia hispana se consolidaba, se lograría que los habitantes de aquellos parajes dejasen de una vez por todas el uso de tales prácticas, pues hasta el momento: "Digo yo ¿qué aprovechaba todos aquellos prometimientos, que, en volviéndose la cabeza, hacían las mismas crueldades?» (Díaz del Castillo, 2011 [1632]: 181, 270, 322).

Sea como fuere, poco antes de la huida de México, la famosa Noche Triste del 30 de junio al 1 de julio de 1520, mientras se batallaba en el interior de la gran urbe, los aborígenes aliados de Cortés y su hueste, tlaxcaltecas y totonacas, fueron acuciados por el hambre, quizá más que los propios castellanos, quienes subsistían por entonces con el reparto de unos cincuenta granos de maíz diarios. El padre Torquemada asegura que aquellos acabarían por comer de los cuerpos de los guerreros mexicas caídos (Torquemada, 1975-1983 [1615], II: lib. IV, cap. LXVIII). En ese caso, ya no se trataría de canibalismo ritual, sino de pura y simple supervivencia. Es más, poco después, una vez abandonada la capital mexica y camino de Tlaxcala, a la altura de la localidad de Tepotzotlan, un acto de canibalismo entre hispanos se sancionó con la orden de Cortés de ahorcar al culpable, quien había abierto el cadáver de un compatriota para comerse el hígado, pero por ruego de los hombres le perdonó (Cervantes de Salazar, 1971 [1914]: lib. IV, cap. CXXVII). Cabe decir que el canibalismo entre cristianos no era desconocido (Piqueras, 2002: 41-51). A título de ejemplo, Pedro Mártir de Anglería relata cómo unos cristianos se comieron a un indio muerto, tal era el hambre que pasaban en la zona del golfo de Urabá (Mártir de Anglería, 1989 [1511-1525]: 160). Y en el caso de la expedición del alemán A. Alfinger, en la exploración de Venezuela, según el testimonio del soldado Francisco Martín, unos soldados hambrientos mataron a una india para comérsela (Friede, 1961: 219 y ss.). Pero es que también se dio un flagrante caso de canibalismo en la terrible expedición de Hernán Cortés a Las Hibueras entre 1524 y 1526. El cronista Antonio de Herrera es el único en citar el caso de uno de los músicos que acom- 
pañaban a la hueste, un tal Medrano, natural de Toledo, quien afirmó que se había alimentado de los sesos de otro músico, un tal Medina, sevillano y tañedor de sacabuche, así como del hígado y los sesos de Bernaldo Caldera y un sobrino suyo, también músicos, fallecidos por hambre. Es de suponer que Cortés no llegó a enterarse en aquel momento, porque de lo contrario Medrano hubiese tenido problemas (Herrera, 1601, década III, libro VII: 292). Por cierto, poco antes de dicho suceso, Cortés ordenó quemar vivo a un indio que había comido carne humana. Como se verá, es obvio que la tolerancia exhibida durante el cerco de México había terminado (Ibídem: 282).

La cuestión caníbal cobra nueva dimensión cuando, una vez recuperadas parte de sus fuerzas en la señoría tlaxcalteca, Cortés se lanzase a su primera campaña por el control del entorno inmediato de esta, con la conquista de Tepeacac, llamada Segura de la Frontera, y los territorios aledaños, donde las guarniciones mexicas resistían y amenazaban la ruta abierta en dirección a Cempoala y Veracruz. Operando en Acatzinco, Cortés permitió que los tlaxcaltecas reanudaran sus prácticas caníbales. Cervantes de Salazar escribió lo siguiente, sin duda con exageración: «Hubo aquella noche para los tlaxcaltecas gran banquete de piernas y brazos porque, sin los asadores que hacían de palo, hubo más de cincuenta mil ollas de carne humana. Los nuestros lo pasaron mal, porque no era para ellos aquel manjar» (Cervantes de Salazar, 1971 [1914]: lib. V., cap. XIII). Algunos testigos, enemigos de Cortés, dijeron en su juicio de residencia que al menos un español probó la carne de indio - extremo desmentido por Juan Álvarez, quien, no obstante, sí asevera que los tlaxcaltecas les ofrecían carne humana - y que era común alimentar con dicha carne a los perros locales, ${ }^{6}$ los cuales a su vez eran comidos por los tlaxcaltecas. También se rumoreó que los castellanos intercambiaban cuerpos de tepeacanecas por comida más convencional con los aliados aborígenes. En concreto, en diversas probanzas de conquistadores como Diego Holguín, Juan Álvarez o Diego de Ávila, se insinuaría que Cortés permitió a sus aliados tlaxcaltecas que se llevasen diversas partes de los cuerpos de los mexicas y sus aliados caídos en el campo de batalla para proceder más tarde a su guiso e ingesta. Una variante, aportada por Ávila, fue afirmar que el de Medellín entregó varios prisioneros tepeacanecas a sus aliados para que fuesen comidos, de modo que cerca del campamento castellano se habilitó un lugar en el que se preparaba la carne de los tepeacanecas para su posterior consumición. Otros testimonios, como los de Bono de Quejo y Diego de Vargas, informaban en sus probanzas sobre el mercadeo de cuerpos de tepeacanecas a cambio de pollos y telas realizado por miembros de la hueste de Cortés, quienes se desplazaban hasta Tlaxcala para tales efectos (testimonios, muchos de ellos de oídas, citados en Polavieja, 1889: 211-212, 236, 263-264, 283, 300-301). El cronista Antonio de Herrera silencia casi todos los actos crueles de Cortés en aquella campaña, aunque refiere el canibalismo entre los tlaxcaltecas (Herrera, 1601, década II, libro X: 352-353). Fernández de

6. Sobre la ingesta de canes por parte de las huestes conquistadoras, véase Piqueras (2006: 186-202, especialmente 194 y ss.). 
Oviedo, asimismo, se hizo eco del canibalismo tras la batalla, típico de aquellas gentes, pero recalcando cómo a Cortés se le olvidó mencionarlo (Fernández de Oviedo, 1853 [1535], II: 392-393). También fray Juan de Torquemada, quien usa las mismas frases que Cervantes de Salazar o, más habitual aún, que Antonio de Herrera, admitió la cuestión del canibalismo consentido por los españoles en momentos de conflicto, además de aceptar la política de guerra a sangre y fuego propugnada por Cortés, así como la esclavitud decretada para tantos vencidos (Torquemada, 1975-1983 [1615], II: lib. IV, cap. LXXVI).

En la última campaña previa al comienzo del sitio de la gran urbe mexica, iniciada el 5 de abril de 1521, con pretensión de dirigirse a Tlalmanalco, Cortés pudo conseguir el concurso, según sus datos, de veinte mil indios aliados (tetzcocanos y tlaxcaltecas), cifra que se dobló cuando los nuevos aliados chalcas se sumaron a la operación. Para Díaz del Castillo, muchos indios aliados convocados por Cortés se fueron acercando a la hueste hispana, pero interesadamente, «á causa del despojo que había de haber, y lo más cierto, por hartarse de carne humana si hubiese batallas, porque bien sabían que las había de haber», a la manera de los cuervos y milanos que, en Italia, seguían a las tropas cuando marchaban de una parte a otra, esperando también las batallas para alimentarse de los cuerpos de los caídos (Díaz del Castillo, 2011 [1632]: 575-576). Tildar a los indios aliados de vulgares carroñeros, cuando el éxito final de toda aquella extraordinaria campaña dependió en buena parte de ellos, no deja de ser una injusticia por parte del cronista.

Con el asedio de México-Tenochtitlan en marcha, cuando relataba los primeros combates del sitio, Fernández de Oviedo volvía a la carga al comentar la barbarie de los aliados de Cortés, pues:

\footnotetext{
Ni podían ver los ojos de los chripstanos é cathólicos más espantable é aborrescida cosa que ver en el real de los amigos confederados el continuo exercicio de comer carne asada ó cocida de los indios enemigos; é aun de los que mataban en las canoas ó se ahogaban, é después el agua los echaba en la superficie de la laguna ó en la costa, no los dexaban de pescar é apossentar en sus vientres (Fernández de Oviedo, 1853 [1535], II: 393).
}

Por supuesto, era barbarie porque no se hacía por necesidad, como ocurrió en Atenas al ser sitiada por Sila en 87/86 a. C., según el relato de Appiano Marcelino que nuestro cronista oportunamente citó (Fernández de Oviedo, 1853 [1535], ॥: 392-393). No obstante, el mexicano era un escenario único, pues si bien en Europa se dieron casos de canibalismo tras largas semanas de asedio entre los afectados (Martínez Martínez, 2013: 129, 138, 147, 150, 206, 266), en el caso de México-Tenochtitlan el canibalismo sería una parte más, y no desdeñable, del botín de guerra.

A la hora de examinar las consecuencias de un asedio como el de la gran urbe mexica, Francisco López de Gómara no dudó en justificar la hecatombe producida, pues los tenochcas:

Eran muchos, comían poco, bebían agua salada, dormían entre los muertos y estaban en perpetua hedentina; por estas cosas enfermaron y les vino la pestilencia, en que murieron infinitos; 
de las cuales también se colige la firmeza y esfuerzo que tuvieron en su propósito, porque llegando a extremo de comer ramas y cortezas, y a beber agua salobre, jamás quisieron paz (López de Gómara, 2007 [1552]: 277).

López de Gómara es autor de un fino análisis, pues asevera que Cortés y los suyos nunca pudieron contemplar el gran número de decesos ocasionados por sus acciones a causa de que los mexicas ocultaban en sus casas a sus muertos, que, por cierto, no se comían, pues de lo contrario no habrían pasado hambre. Es decir, que el propio cronista desmiente que los mexicas fueran caníbales; en todo caso, serían caníbales rituales, como ya se ha señalado (López de Gómara, 2007 [1552]: 277 y ss.).

Ahora bien, Díaz del Castillo, quien no iba a dejar pasar una sola observación de López de Gómara si esta le merecía un reproche, rememoraba en su crónica que los mexicas sí comían las carnes de españoles y tlaxcaltecas en la guerra. Pero ¿se puede asegurar realmente que la obtención de prisioneros para sacrificar e ingerir después sus cuerpos fue uno de los grandes estímulos de la batalla por México-Tenochtitlan? En un pasaje no demasiado concluyente, parece dar a entender Díaz del Castillo que Cortés hizo saber a sus aliados, en especial a las gentes de Cholula y Huejotzingo, que, si le ayudaban a poner cerco a la capital mexica, también gozarían de los "despojos" que los tlaxcaltecas habitualmente llevaban a su señoría: "se les hizo saber, de sus mismos indios, cómo siempre iban de nuestro real cargados de despojos [los tlaxcaltecas] de las entradas que hacíamos". Y, desde luego, los mexicas de Cuauhtémoc no se iban a privar de sacrificar y desmembrar a los castellanos tomados prisioneros, pues una vez ofrecidos sus corazones y su sangre a los dioses, se comían las piernas y los brazos, siempre según el cronista de Medina del Campo (Díaz del Castillo, 2011 [1632]: 603, 648).

Cervantes de Salazar, quien copia los datos de Gómara, no duda en doblar el número de mexicas muertos en el asedio, hasta alcanzar los doscientos mil. Su aportación más destacable, se me antoja, es el análisis de las muertes de los mexicas:

Notaron los nuestros una cosa no digna de olvidar, que los recién muertos hedían y después no hacían gusanos, tanto que como carne momia se enxugaban en muy breve, de manera que tomando a uno por el pie le levantaron entero, como si fuera hecho de cañahexas. La causa desto se cree que era el comer poca carne o ninguna, sino era la que de cuando en cuando comían de los que sacrificaban, porque de la de los suyos siempre se abstuvieron; su cotidiana comida era tortillas y agi [aji], comida muy enxuta y que engendraba pocos humores, y caer los cuerpos sobre tierra salitrosa. Murieron muchos nobles, porque fueron los que más porfiaron. Bebían ruin agua, mas no de la salada, porque es peor que la de la mar. Dormían entre los muertos, de cuyo hedor inficcionados morían luego, inficcionando a otros (Cervantes de Salazar, 1971 [1914]: lib. v, cap. CXCVII).

Por cierto, solo dos religiosos cronistas, los padres Bernardino de Sahagún y Juan de Torquemada, constatan en sus obras cómo algunas madres mexicas devoraron a sus hijos, tal era su necesidad en el transcurso del asedio. William $\mathrm{H}$. Prescott, quien indagó en el manuscrito de la magna obra de Bernardino de 
Sahagún Historia general de las cosas de la Nueva España, en el libro duodécimo, capítulo XXXIX, leyó lo siguiente: «De los niños, no quedó nadie, que las mismas madres y padres los comían» (Sahagún, citado en Prescott, 2004 [1843]: 508, nota 192). La frase es copiada por el padre Torquemada, pero este solo hace referencia al canibalismo maternal con respecto a sus hijos (Torquemada, 1975-1983 [1615], II: lib. IV, cap. c). Prescott ya se fijó en su momento en un texto del Deuteronomio que hace referencia directa a las madres, quienes, en los asedios, acabarían por comer no solo las placentas, sino también a sus propios hijos (Prescott, 2004 [1843]: 508, n. 192). Flavio Josefo, referencia principal para muchos cronistas cuando comparan el asedio de Jerusalén por los romanos con la hazaña cortesiana, comenta la opción de estos de batir a los habitantes de la urbe merced al hambre y la sed. El autor hebreo subrayaba en su relato que ciertas mujeres no dudaban en sustraer la comida de sus hijos, aun siendo estos pequeños y estar al borde de la muerte, para comer ellas, aparte del caso de María, hija de Eleazar, quien una vez refugiada en Jerusalén, desengañada de todo y de todos, a las puertas de la muerte a causa del hambre, acabó por comerse al hijo que aún amamantaba (Josefo, 1891, tomo II: lib. VI, cap. XI y lib. VII, cap. VIII).

En cualquier caso, los momentos finales del asedio de la gran urbe mexica hubieron de ser espeluznantes. La descripción que nos hace Cortés es terrible (de la lucha del día 11 de agosto, dos días antes de rendirse Cuauhtémoc), con unos mexicas que apenas hallaban con qué defenderse, pues habían agotado las flechas y jabalinas, mientras saltaban entre cadáveres de azotea en azotea para pelear con rodela y macana contra sus enemigos hasta el último hombre. $Y$ añade:

[...] aquel día se mataron y prendieron más de cuarenta mil ánimas; y era tanta la grita y lloro de los niños y mujeres, que no había persona a quien no quebrantase el corazón, y ya nosotros teníamos mas que hacer en estorbar a nuestros amigos que no matasen ni hiciesen tanta crueldad que no en pelear con los indios; esta crueldad nunca en generación tan recia se vio, ni tan fuera de toda orden de naturaleza, como en los naturales de estas partes (Cortés, 1985 [15221523]: 147-148).

Y al mismo tiempo recordaba cómo ellos eran apenas novecientos hombres y los auxiliares ciento cincuenta mil, de suerte que no podían - no se atrevieron - a entorpecerles en sus designios. Y, para colmo de males, el de Medellín cifra en quince mil el número de fallecidos al día siguiente. Pedro Mártir de Anglería también se hizo eco del asunto cuando escribió:

\footnotetext{
Setenta días continuos fue hostilizada por todos lados, y por detrás y por delante [...] cuanto más sangriento había sido el estrago, tanto más abundante y opípara cena tenían los guaxocingos, tlaxcaltecas y demás auxiliares de allí, que acostumbraban a sepultar en sus vientres a los enemigos que caen en la batalla, y Cortés no se habría atrevido a impedirlo (Anglería, 1989 [1511-1525]: déc. v, cap. vilI).
}

Toda la operación que condujo a la caída de México-Tenochtitlan se puede calificar como una gran matanza, pero no fue la única, a tenor de lo explicado por los cronistas. 


\section{Masacres}

En el Anáhuac prehispánico no era extraño que se perpetrasen masacres. El gran tlatoani Ahuitzotl, al derrotar las revueltas de antiguos tributarios, como TeIoloapan, Oztoman y Alahuiztlan en 1488 y 1489, procedió a masacrar a los habitantes de las dos últimas (menos a los niños, que fueron distribuidos por todo el imperio), dado que los de Teloloapan alegaron que habían sido engañados e incitados a la rebelión por los otros dos tributos. El prestigio del tlatoani quedó reforzado por estos hechos de guerra, así como por la consecución de una gran masa de cautivos que fueron inmolados en la inauguración del gran templo central de México-Tenochtitlan, una obra de gran envergadura iniciada por Moctezuma I (Carrasco, 1996: 59 y ss.; Bueno Bravo, 2007: 70 y ss.). También los tarascos pudieron perpetrar grandes masacres con los civiles no combatientes que han sido interpretadas siempre como sacrificios, cuando solo tenían en común con aquellos la cardioectomía como fórmula para administrar la muerte (Cervera Obregón, 2017: 74-89).

Como he mencionado al inicio de este trabajo, fuera de las conocidas masacres de Cholula y del mes de tóxcatl (mayo de 1520) protagonizada por Pedro de Alvarado, ambas bien conocidas, la acción militar de Hernán Cortés entre agosto de 1520 y abril-mayo de 1521 incluyó la perpetración de diversas masacres con la intención de sujetar el entorno primero de la localidad de Tepeacac (rebautizada como Segura de la Frontera) y, más tarde, del ámbito más inmediato al lago de Tetzcoco, siempre con la estrategia in mente de desarticular las posibles ayudas que pudiesen obtener en tales territorios los mexica cuando fuesen cercados en su gran capital. En estas operaciones se iban a dar habitualmente los tres supuestos que estamos analizando: se masacraba a los combatientes; se entregaban cierto número de prisioneros a los aliados aborígenes, quienes los sacrificaban y, en teoría, también los deglutían; y, por último, se esclavizaba, práctica que se extendió, sobre todo, con relación a mujeres y menores.

Cuando operaba en las cercanías de Tepeacac, tras masacrar a los defensores de Zacatepec, quizá unos cuatrocientos, una de las primeras y duras medidas cortesianas, según relata Cervantes de Salazar, fue eliminar a las guarniciones tepeacaneca y mexica de Acatzingo. En dicha localidad, cuando el caudillo extremeño se hizo con algunos prisioneros, desde lo alto de unos aposentos, «y para espantar a los demás, hacíalos echar de allí abaxo, donde se hacían pedazos, porque los aposentos eran muy altos y los arrojados daban sobre piedras"». A otros muchos se les lanceó o fueron atravesados por picas; e, incluso, hubo casos de aperreamiento (Cervantes de Salazar, 1971 [1914]: lib. v, cap. XIII y ss.). En palabras de Bernardino Vázquez de Tapia, Cortés y sus hombres, asentados en Acatzingo, recorrieron todo el territorio de Tepeacac y se impusieron a aquellos pueblos («y les hicimos de tal manera la guerra, que les hicimos que se arrepintiesen de lo pasado y pidiesen la paz, la cual se aceptó con las condiciones que el marqués les puso») (Díaz et al., 1988: 148). En siguientes conquistas la misma tónica se mantuvo. En el juicio de residencia de Cortés, Vázquez de Tapia aseguró que en Cachula (Quauhtinchan) y Tecamachalco aquel ordenó separar a los hombres, unos dos mil, de las mujeres y los niños, sobre los cuatro 
mil, y mandó seguidamente la ejecución sumaria de los primeros y que se esclavizara a los segundos (Vázquez de Tapia, citado en García, 1901: 234; López Rayón, 1852, I: 58-60). Otro testigo en el juicio de residencia, Francisco Flores, era de la opinión de que los castigos empleados fueron convenientes «para la paçificacion de la tierra, e por ser la cosa tan nueva conbenya hacerse aquello que se hizo e mucho mas, para poner temor a los naturales, para que no hiciesen daño en los españoles, e no quebrantasen las palabras de paz que diesen» (Thomas, 1994: 482). Y un tercer testimonio, el de Francisco Verdugo, elevaba a tres mil los muertos en Tepeacac (Thomas, 2001: 271).

Desde Tepeacac, la campaña se mantuvo con idéntica intensidad por otros cuarenta días. Antonio de Herrera, habitualmente muy parco a la hora de relatar atrocidades de sus compatriotas, no dejó de reconocer que Cortés fue quemando los pueblos de la comarca «para más brevemente traerlos a obediencia», y que, una vez dominada Tepeacac, comenzó a enviar «bandas de gente a correr la tierra y destruyrla» (Herrera, 1601, década II, libro x: 354-356). Uno de sus capitanes, Diego de Ordaz, por ejemplo, empleó a doscientos españoles y los aliados indios que necesitó, sin precisarse cuántos, y hasta en cinco ocasiones atacó Tecamachalco hasta derrotarla. Otra ciudad destruida a sangre y fuego sería Acapetlahuacan. Cortés reconoció medio millar de muertos en estas correrías, pero en la época se habló de quince o veinte mil fallecidos y otros tantos esclavizados, cifras que parecen un tanto exageradas, aunque la de Cortés es demasiado reducida, me da la impresión.

Poco después sufriría las iras cortesianas Quauhtinchan, una urbe fuertemente amurallada. Cristóbal de Olid fue el encargado inicial de portar a buen término su rendición, si bien Cervantes de Salazar insinúa que los responsables iniciales de esta operación fueron Diego de Ordaz y Alonso de Ávila, y no Cristóbal de Olid. «Volvieron estos Capitanes con presa de más de dos mill hombres y mujeres, aunque al principio, por espantar a los demás, no se daba vida a hombre», escribió el cronista (Cervantes de Salazar, 1971 [1914]: lib. v, caps. XVIIXXI). Por cierto, en el juicio de residencia cortesiano se alegó que Cristóbal de Olid llevó en dicha ocasión una gran cantidad de aborígenes presos, de los cuales «hizo apartar de los dichos indios, quatrocientos hombres, que heran para pelear, e los fizo matar todos e los otros que quedaron que heran mujeres e niños, los fizo todos esclavos» (Manzo Robledo, 2013: 190). Como matanza califica López de Gómara la operación, pues los vecinos se sumaron, efectivamente, a la masacre y mataron a casi toda la guarnición mexica. Cuando los mexicas reaccionaron, intentando tomar de nuevo la localidad, es cuando se produjo lo que también Cervantes de Salazar estima como matanza, "que fue una de las grandes que en mexicanos se había hecho». Además:

Los nuestros, siguiendo la victoria, saquearon todo cuanto toparon sin dexar cosa; quemaron las casas, en las cuales hallaron muchas vituallas, tomaron, así de los muertos como de otros que prendieron, ricos plumajes, argentería, joyas de oro y plata, piedras presciosas, muchas de las cuales parescían porque lo debían [ser], de las que los nuestros habían perdido a la salida de México (Cervantes de Salazar, 1971 [1914]: lib. v, cap. XxI). 
Tras aquel lance tan favorable, la toma de Quauhtinchan, Cortés y los suyos descansaron tres días en Tepeacac. Luego, la campaña se reanudó. La presión sobre los mexicas continuó con la toma de Itzocan, donde casi toda su guarnición -Cortés la evaluó en cinco o seis mil guerreros- pereció; de esta forma, Cortés no solo adquiría reputación entre los indios e iba controlando las tierras en el entorno de México-Tenochtitlan, sino que además destruía sistemáticamente todas las guarniciones mexicas que se le oponían, sabedor de que, una vez eliminadas, dichas tropas no podrían defender su capital. Una de las medidas de Cortés cuando tomaba una localidad era quemar sus templos. Lo explica Cervantes de Salazar:

\footnotetext{
Quemó Cortés luego los templos e ídolos, así por quitar las fuerzas a sus enemigos como por el menosprecio de su religión vana. Hacía esto Cortés cada vez que los pueblos se le ponían en defensa; y así, los que de paz se le daban, lo primero que pedían era que no les quemase los templos ni derrocase sus ídolos. Condescendía con ellos, porque entonces vía que no era tiempo de hacer otra cosa (Cervantes de Salazar, 1971 [1914]: lib. V, cap. XXII).
}

En Itzocan, por ejemplo, dijo haber quemado un centenar de «mezquitas y oratorios", pero la frase del de Medellín admite otra lectura: las calcinó no solo por ser templos paganos, sino también por ser construcciones «muy fuertes con sus torres», es decir lugares que serían fáciles de defender en caso de rebelarse la ciudad. Además, contaba con defensas naturales y otras construidas por el hombre, de ahí la necesidad de controlar lugares como este (Cortés, 1985 [1522-1523]: 92-93).

Victorias como las de Itzocan y algunas otras, como las obtenidas en Jalatzinco y Zacatami (o Zautla) o en Xocotlan, en jornadas posteriores, obtuvieron los resultados apetecidos y esperados por el caudillo extremeño. Según Cervantes de Salazar, tras la toma de Itzocan, y antes de salir la hueste cortesiana y sus aliados aborígenes de la localidad:

[...] era tanta la fama y nombre que cobró, que vinieron por sus mensajeros a la obediencia ocho o diez pueblos bien lexos de allí a darse por sus amigos y servidores, diciendo que no habían muerto cristiano alguno ni tomado armas contra ellos (Cervantes de Salazar, 1971 [1914]: lib. v, cap. XXIII).

Incluso desde Oaxaca llegaron caciques a prestar ante Cortés juramento de fidelidad y para hacer causa común contra los mexicas.

Tras pacificar la zona, Cortés decidió centrar su atención en el entorno del lago Tetzcoco, una vez ocupada la localidad del mismo nombre en enero de 1521. El primer objetivo de esta otra larga campaña de castigo que duraría cinco meses fue Iztapalapa. Según el propio caudillo de Medellín, tras superar a las tropas enemigas fuera de la ciudad, tomaron la urbe al asalto y persiguieron a sus habitantes hasta que muchos huyeron en canoas, pues dos terceras partes de las casas de la localidad estaban construidas sobre el lago. Y se desencadenó la matanza. En términos del caudillo: 
[...] les tomamos muchas casas de las que estaban en al agua, y murieron en ellos más de seis mil ánimas, entre hombres, mujeres y niños, porque los indios, nuestros amigos, vista la victoria que Dios nos daba, no entendían en otra cosa, sino en matar a diestro y siniestro (Cortés, 1985 [1522-1523]: 104).

También la toma de Yacapichtla degeneró en matanza. Era esta una localidad construida en alto, en una zona poco apta, pues, para el uso de los caballos. Contaba con guarnición mexica y por ello la resistencia fue feroz. El comandante hispano, Gonzalo de Sandoval, resultó herido, como la mayoría de sus hombres, puesto que los aborígenes aliados parecían ser renuentes a asaltar posiciones difíciles, como era aquella. El caso es que la urbe se ocupó al asalto, con todo lo que ello conlleva. Cuando una matanza acontecía, cronistas como Díaz del Castillo se apresuraban en la búsqueda de fórmulas mitigadoras del espanto. En este caso, aseguraba, con una cierta verosimilitud, no obstante, que sus compatriotas dejaron de acuchillar indios una vez vencida su resistencia, pues su obsesión era entonces «buscar una buena india o haber algún despojo» (Díaz del Castillo, 2011 [1632]: 569). Pero añade que matar indios indefensos les parecía una crueldad. Lo ocurrido, a mi juicio, fue más bien que, una vez derrotado el contrario, no deseaban que los indios aliados prolongasen una matanza que podía privarles de obtener algunos esclavos, sobre todo mujeres. Pero un ufano Hernán Cortés explicó el asunto en otros términos:

\footnotetext{
Y como los indios nuestros amigos los siguieron y los enemigos se vieron de vencida, fue tanta la matanza de ellos a manos de los nuestros, y de ellos despeñados de lo alto, que todos los que allí se hallaron afirman que un río pequeño que cercaba casi aquel pueblo, por más de una hora fue teñido en sangre, y les estorbó de beber por entonces, porque como hacía mucho calor tenían necesidad de ello (Cortés, 1985 [1522-1523]: 112).
}

Díaz del Castillo negó este último extremo, pero sin acusar a Cortés de transmitir falsas informaciones a López de Gómara. Para él, lo ocurrido fue muy distinto: los mexicas heridos que bajaban del peñón y se refugiaban en una quebrada por donde fluía un arroyo se iban desangrando, y tintaron el agua con su sangre, «pero no duró aquella turbieza un Ave María» (Díaz del Castillo, 2011 [1632]: 570). Se intuye que otra cosa le contaron a Cortés, como al propio Bernal Díaz, ambos testigos de oídas en este caso, pero López de Gómara no dudó en propagar esa imagen tan potente como es un río tinto en sangre del enemigo vencido. También Fernández de Oviedo aprovechó la alegoría de la derrota del enemigo que vierte tanta sangre ${ }^{7}$ como para enturbiar las aguas cercanas para comparar una vez más a Cortés con un héroe romano: en este caso, con Mario, cuando derrotó a los cimbrios, según el relato de Plutarco (Fernández de Oviedo, 1853 [1535], I: 365).

7. Sobre la imagen de la sangre en los imaginarios bélicos hispánicos, desde la primera Edad Moderna a la Contemporánea, véase Casado-Neira (2016: 98-111). 
A inicios de abril de 1521, cuando Cortés estaba combatiendo en Tlalmanalco, cerca de localidades encontradas abandonadas a causa del temor que inspiraba en sus habitantes, como Yahutepec, de nuevo se produjeron momentos de enconada lucha en los peñoles de Tlayacapan y otros enclaves, por lo que el de Medellín volvió a sus prácticas aterradoras. Así, el contratiempo habido en los peñoles, cuya toma le costó al caudillo extremeño media docena de muertos españoles y muchos heridos, lo vengó Cortés con la toma de Xiuhtepec, que encontró muy descuidada y sin vigilancia, pues la ocupó sin problemas. Hizo muchos prisioneros, mató a otros tantos y, como en dos días no se personaron sus dirigentes para dar la obediencia exigida, ordenó quemar la localidad. Díaz del Castillo asegura que fue acción premeditada: «e porque otros pueblos tuviesen temor dello, mandó poner fuego a la mitad de las casas que allí cerca estaban» (Díaz del Castillo, 2011 [1632]: 583). Todo parece indicar que Cortés olvidaba lo antes posible cualquier fracaso en materia militar con una acción de la máxima contundencia.

Cuernavaca fue tomada al asalto y resultó saqueada y semidestruida por el fuego. Cortés asegura que se mató a muchos aborígenes merced al alcance que se les dio con los caballos y los indios auxiliares. Al caer el día se personaron veinte señores a solicitar el perdón del caudillo extremeño. Este lo concedió gustoso, pero no sin antes permitir a su gente un merecido descanso en la urbe para reponerse de semejante jornada. Un comentario del mismo caudillo acerca de lo acontecido en Cuernavaca puede aclarar algunas cosas. Aseguró Cortés que:

Estos indios y los otros que venían a darse por vasallos de vuestra majestad, después de haberles quemado y destruido sus casas y haciendas, nos dijeron que la causa porque venían tarde a nuestra amistad era porque pensaban que satisfacían sus culpas en consentir primero hacerles daño, creyendo que hecho no teníamos después tanto enojo de ellos (Cortés, 1985 [1522-1523]: 116).

Si es cierto, fue una verdadera lástima, pues se podrían haber ahorrado muchas vidas. No obstante, el cronista Cervantes de Salazar recuerda que a los habitantes de todas estas últimas ciudades conquistadas "Cortés los rescibió de buena voluntad, porque en ellos se había hecho buen castigo, y así no les dixo más de que por el castigo pasado verían cuánto les convenía perseverar en el amistad que ofrescían». De alguna forma, el terror al mexica era sustituido por el terror al castellano (Cervantes de Salazar, 1971 [1914]: lib. v, cap. CXI).

La batalla por Xochimilco fue muy dura. En la incursión realizada en el entorno sur del lago Tetzcoco, Cortés procuró medir fuerzas con el contrario, analizar su capacidad de respuesta táctica, al tiempo que probaba la valía de sus hombres, tanto europeos, como la respuesta militar que recibiría de sus huestes aborígenes auxiliares. Y la ciudad no se salvó. Tras una dura resistencia, cuando los guerreros mexicas y las habitantes de la urbe terminaron por retirarse, el caudillo extremeño y los suyos hicieron lo propio, no sin antes pegarle fuego a la ciudad. Debió de ser un espectáculo dantesco. No pudo dejar de escribir: «y al cabo, dejándola toda quemada y asolada, partimos, y cierto era mucho para 
ver, porque tenía muchas casas y torres de sus ídolos de cal y canto» (Cortés, 1985 [1522-1523]: 118). Fue el último combate realmente relevante antes de iniciarse el ataque final por la conquista de México-Tenochtitlan.

\section{Esclavitud}

Para contentar a los integrantes de su hueste, muchos de ellos recelosos tras la pérdida total del botín en oro acumulado tras la huida de México, la famosa Noche Triste, Hernán Cortés, siempre hábil y práctico, entendió que una buena salida, de las únicas de hecho, sería permitir el reparto de prisioneros de guerra. Es muy significativo un apunte de Cervantes de Salazar: el caudillo extremeño logró acallar ciertas quejas de los hispanos supervivientes de su hueste cuando se hallaban descansando en Tlaxcala al prometerles que «en la guerra de Tepeaca harían lo que quisiesen» (Cervantes de Salazar, 1971 [1914]: lib. v, cap. v). Es más, cuando se acercaba a Tepeacac, el de Medellín amenazó a sus habitantes, en caso de resistencia y si no expulsaban a la guarnición mexica, con una guerra a sangre y fuego y con esclavizar a los prisioneros habidos en la misma con la excusa de que eran caníbales. Llegó a levantar un auto ante escribano en el que daba cuenta de tales medidas. Simplemente, Tepeacac era la primera localidad que se iba a enfrentar con esta nueva política. Escribe Cortés: «Y también me movió a hacer los dichos esclavos por poner algún espanto a los de Culúa [México-Tenochtitlan] y porque también hay tanta gente, que si no se hiciese grande el castigo y cruel en ellos, nunca se enmendarían jamás» (Cortés, 1985 [1522-1523]: 88). En palabras de Díaz del Castillo, tras amenazarles los tepeacanecas con comerse a todos los españoles hechos prisioneros, Cortés acordó «que se diesen por esclavos a todos los aliados de México que hobiesen muerto españoles» (Díaz del Castillo, 2011 [1632]: 504).

Tras la rendición de Tepeacac, muchos de cuyos habitantes, así como la guarnición mexica, habían huido de hecho hacía un tiempo a México-Tenochtitlan, el caudillo de Medellín mandó aderezar un hierro en forma de letra G, con el significado de Guerra, para herrar en el rostro a todos aquellos tomados presos en el conflicto y esclavizarlos. En realidad, Cortés y sus hombres comenzaron a tomar como esclavos solo a las mujeres y a los indios jóvenes de ambos sexos, mientras que los hombres, más difíciles de guardar y hacer trabajar, eran el botín de los aliados (Díaz del Castillo, 2011 [1632]: 504-505). Cabe decir que para el cronista Antonio de Herrera la política del caudillo extremeño para con los esclavos era justo la contraria: «mandó Cortés vender a muchos que había prendido, y herrarlos, salvo a las mujeres y niños, conforme a su costumbre, aplicando una parte a su ejército, y otra a la república de Tlascala». Herrera nos ofrece esta explicación por seguir en su relato a Cervantes de Salazar (Herrera, 1601, década II, libro x: 353). López de Gómara apunta que si Cortés ordenó la esclavitud de todos los tepeacanecas fue por la rebeldía que habían protagonizado, pero también «porque temiesen otros, y porque eran muchos, y porque si así no los trataba, luego se rebelaran» (López de Gómara, 2007 [1552]: 218). Cervantes de Salazar (1971 [1914]: lib. v, cap. XIV) asegura: «De los esclavos entregó el 
quinto a los Oficiales del Rey; los demás repartió entre los que lo habían menester y otros invió a Tlaxcala para que los tuviesen en guarda hasta que él volviese». Los esclavos se vendieron a 10 pesos por cabeza. Otro testimonio, procedente al igual que los ya mencionados del juicio de residencia de Cortés, el de Antonio Serrano de Cardona, alias Villarroel, puntualiza Díaz del Castillo: según Serrano, tras meter a «sacomano» toda Tepeacac y su comarca, haciendo esclavos a diestro y siniestro, en Acatzingo «a las mugeres e mochachos el dicho D. Fernando Cortés mandó herrar por esclavos e a los honbres mandó matar a lanzadas e a cuchilladas e asy se fizo» (citado en García, 1901: 233). Según Díaz del Castillo, en Quauhtinchan, lugar donde habían matado a varios españoles meses atrás, «hobimos muchos esclavos». En aquellas jornadas, cuando se conseguía vencer la resistencia local, «allegáronse muchas indias e muchachos que se tomaron por los campos y casas, que hombres no curábamos de ellos, que los tascaltecas llevaban por esclavos» (Díaz del Castillo, 2011 [1632]: 504-505).

Como se ha señalado antes, la campaña se mantuvo, y solo en Tecamachalco Diego de Ordaz logró hasta dos mil quinientos prisioneros. Desde dicha localidad, «Los españoles hicieron muchas correrías donde prendieron y mataron muchos de los enemigos» (Cervantes de Salazar, 1971 [1914]: lib. v, cap. XIV). Y todo aquel que hubiera luchado antes de entregarse corría el riesgo de ser esclavizado y de que lo fueran, en especial, sus mujeres e hijos. Eso ocurrió en Jalatzinco, Xocotlan o Acapetlahuacan. Y el caso es que tal política funcionaba, pues, como se ha comentado antes para el caso de Itzocan, pueblos lejanos se adelantaban a posibles ataques y presentaban su rendición y colaboración a Cortés (Cervantes de Salazar, 1971 [1914]: lib. v, cap. XXIII).

La cuestión de la esclavitud como botín de guerra, y no solo como castigo para el considerado rebelde, se percibe en el momento en que se insiste en la obtención de mujeres para la hueste europea. «Y allí en aquel pueblo se hobieron muy buenas indias», escribe, una vez más, Díaz del Castillo refiriéndose a lo acontecido en Xaltocan semanas después de los ataques a Tepeacac y su entorno (Díaz del Castillo, 2011 [1632]: 557). En realidad, cuando los oficiales de Cortés, como Olid, Sandoval y otros, regresaron a Tepeacac con sus respectivos botines humanos, asimismo todos los integrantes de la hueste se vieron obligados en un plazo de dos días a entregar a todas las mujeres, muchachos y muchachas que tuviesen en su poder. El problema estuvo en que, cuando se iban a repartir entre todos, se supone que de forma equitativa, los oficiales «habían ya escondido y tomado las mejores indias, que no [a]pareció allí ninguna buena, y al tiempo de repartir dábannos las viejas y ruines». Es lógico entender que las murmuraciones cundieron rápidamente, sobre todo, como señala Bernal Díaz, cuando «el pobre soldado que había echado los bofes y estaba lleno de heridas por haber una buena india, y les habían dado naguas y camisas, habían tomado y escondido las tales indias". La solución hallada por Cortés, siempre hábil y resolutivo, fue sacar a las indias en pública almoneda, «y la buena que se vendería por tal, y la que no lo fuese, por menos precio, y de aquella manera no tendrían que reñir con el» (Díaz del Castillo, 2011 [1632]: 522-523). 
La problemática de la esclavitud volvería a estar en el candelero tras la toma de Tetzcoco en enero de 1521. Aunque la mayoría de los testimonios de los cronistas dan a entender una entrada pacífica, al parecer Cortés se molestó muchísimo al encontrar una ciudad semideshabitada, pues una amplia mayoría de sus naturales habían huido precipitadamente a México-Tenochtitlan. Por ello, según algunos testigos del juicio de residencia cortesiano, el de Medellín dio orden de saquear la ciudad, con lo que obtuvo un buen botín, y de herrar como esclavos a mujeres y niños (pues mataron a los pocos hombres que hallaron) para venderlos en pública subasta. Si bien, lo que molestó de veras es que no hubiese reparto entre los hombres de semejante botín (López Rayón, 1852, I: 198-199).

En marzo de dicho año, Díaz del Castillo aseveraba, no sin escandalizarse, que no solo se mantuvo la práctica de apartar el quinto real, sino que también se aplicaba la del quinto que obtenía Cortés del botín habido, así como la de retirar una parte menor, pero sustancial, para sus oficiales más leales. El resultado, en cuanto al reparto de las féminas, era que, de nuevo, «nos desaparecieron las más bellas». Es decir, que no todas las mujeres llegaban a la subasta pública como se había prometido. Acusa Bernal Díaz a los oficiales del rey presentes, quienes nunca fueron rectos en su cuidado de semejante negocio, que fue de mal en peor. El resultado de todo ello era previsible: «muchos soldados que tomábamos algunas buenas indias, porque no nos las tomasen, como las pasadas, las escondíamos y no las llevábamos a herrar, y decíamos que habían huido». En otras ocasiones se llevaban a herrar en secreto, se pagaba el quinto del rey y asunto resuelto. O bien se decía que la india (o indias) en cuestión no era prisionera de guerra esclavizable, sino sirvienta naboría, es decir, mujer al servicio de la tropa procedente de las ciudades aliadas y exenta, por lo tanto, de ser esclavizada. Y un detalle muy interesante: como algunas indias llevaban con la hueste varios meses en el momento de la subasta pública a fines de marzo de 1521 , conocían perfectamente quien las trataba bien o mal, quien era caballeroso y quien no lo era, de modo que al ser conscientes de que el indeseable de turno podía hacerse con ellas para siempre, como legítima posesión, no dudaban en huir del campamento hispano. También ocurría con las indias naborías, pues el maltrato alcanzaba a cualquier fémina, de la condición que fuera, si la persona era de una rudeza notoria (Díaz del Castillo, 2011 [1632]: 572-573).

Y por tercera vez tras la ocupación de Xochimilco, justo antes del inicio del ataque final a México-Tenochtitlan en mayo de 1521, volvió a haber problemas: se procedió una vez más a la pública subasta de las indias habidas en la última campaña con los habituales excesos de los oficiales, que, como en las ocasiones anteriores, «si eran hermosas y buenas indias las que metíamos a herrar, las hurtaban de noche del montón, que no [a]parecían hasta de ahí a buenos días, y por esta causa se dejaron de herrar muchas piezas que después teníamos por naborías» (Díaz del Castillo, 2011 [1632]: 601).

En definitiva, determinados testigos (Alonso Pérez, Marcos Ruiz, Domingo Niño, Antón de Arriaga), declarantes todos ellos en el juicio de residencia cortesiano, aseveraban que la norma respecto a la esclavitud fue la explicada por Andrés de Monjaraz: 
A las treynta e seys preguntas dixo que en la cibdad de Tezcuco y en la provincia de Tepeaca e en Chelula e en Guastepeque y en Cuernavaca vido este testigo quel dicho D. Fernando Cortes syn requerir a los yndios de las dichas provincias les fizo guerra e fizo muchos dellos esclavos e mato mucho numero dellos (López Rayón, 1853, II: 68).

\section{Conclusiones}

Hernán Cortés hubo de ser muy consciente, tras los primeros compases de la campaña que condujo a la conquista de México-Tenochtitlan en agosto de 1521, de que iba a necesitar no solo el concurso de sus aliados aborígenes, sino también la plena cooperación de la gente de su hueste, muchos de los cuales habían sido integrantes de la de Pánfilo de Narváez. Convencidos estos últimos de los beneficios que les podría reportar su apoyo al caudillo de Medellín, no es menos cierto que, en determinados lances de los combates que se sucederían en los meses comprendidos entre abril y mayo de 1520 y la derrota mexica de agosto de 1521, su rendimiento militar y su actitud iban a flaquear. De ahí que, junto con la necesidad de premiar a sus más fieles seguidores, Cortés intentase contentarlos a todos mediante el reparto del botín que se iba consiguiendo.

Ya hemos visto que la esclavitud de numerosos prisioneros de guerra, en su mayoría mujeres y gente joven, se saldó con numerosas críticas, al menos en la memoria y en la pluma de Bernal Díaz del Castillo, que describe con certera verosimilitud los excesos cometidos por Cortés, algunos de sus protegidos y los oficiales reales a la hora de establecer un mecanismo de compra-venta eficaz y aceptable de las esclavas obtenidas. En cambio, y eso demostraría también su importancia, los aliados aborígenes, cada vez más numerosos, no dudaban en hacerse con todos aquellos objetos y productos que legítimamente podían considerar como sus ganancias en aquella empresa, y ello incluía la obtención de prisioneros de guerra, muchos de los cuales, según los testimonios señalados, acabarían en sus estómagos. Cortés habría, pues, de administrar un canibalismo sobrevenido que, en ningún caso, a pesar del rechazo que pudiera manifestarse puntualmente acerca del mismo, podía permitirse erradicar. Al menos no antes de obtener la gran victoria final. Por otro lado, la perpetración de cierto número de masacres y/o matanzas, destrucción de ciudades y esclavización de poblaciones a lo largo de una doble campaña, desarrollada entre agosto y diciembre de 1520 en una primera fase, y entre enero y mayo de 1521 en una segunda, fue un mecanismo bastante obvio de obtener la rendición y la posterior colaboración forzada de numerosos territorios y poblaciones, que de esa forma fueron sustraídos de la lógica imperial mexica. Así las cosas, las campañas cortesianas preparatorias del gran asedio de México-Tenochtitlan adquieren una importancia crucial y nos permiten adquirir una visión más profunda y cabal sobre la persona del caudillo extremeño, quien presenta una biografía heroica con tantas luces como sombras. 


\section{Bibliografía}

Aııı, Antonio (2009). La «verdadera» visión de los vencidos. La conquista de México en las fuentes aztecas. Alicante: Publicaciones Universidad de Alicante.

AlCALÁ, fray Jerónimo de (2008). Relación de Michoacán. Estudio introductorio de Jean Marie G. Le Clézio. Zamora: El Colegio de Michoacán.

AngleríA, Pedro Mártir de (1989 [1511-1525]). Décadas del Nuevo Mundo. Madrid: Polifemo.

BuEno Bravo, Isabel (2007). La guerra en el Imperio azteca. Expansión, ideología y arte. Madrid: Universidad Complutense de Madrid.

Carrasco, Pedro (1996). Estructura político-territorial del Imperio tenochca. La triple alianza de Tenochtitlan, Tetzcoco y Tlacopan. México D. F.: El Colegio de México / Fondo de Cultura Económica - Fideicomiso Historia de las Américas.

CASAdo-NeIRA, David (2016). «Sangres combatientes españolas, sangres del dolor: la sangre en el imaginario de la violencia bélica». Imagonautas, Cohauila, 7, págs. 98111.

Cervantes de Salazar, Francisco (1971) [1914]. Crónica de la Nueva España, BAE vols. 244-245, edición de Manuel Magallón. Madrid: Atlas.

Cerviera Obregón, Marco A. (2007). El armamento entre los mexicas. Madrid: Consejo Superior de Investigaciones Científicas, col. Anejos de Gladius, 11.

Cervera Obregón, Marco A. (2017). «Derecho en la guerra: el trato a los combatientes y no combatientes en los conflictos armados mexicas». Reflectio, Ciudad de México, 9-I, págs. 74-89.

ClendinNen, INGA (1991). «"FIERCE AND UnNATURAL CRUELTY”. Cortés and the conquest of Mexico». Representations, Berkeley, 33, págs. 65-100.

CORTÉS, Hernán (1985 [1522-1523]). Cartas de relación. Barcelona: Sarpe.

DeCLERCQ, Stan J. L. (2018). In mecitin inic tlacanacaquani: «Los mecitin (mexicas): comedores de carne humana». Canibalismo y guerra ritual en el México antiguo. Tesis doctoral, UNAM.

DíAz, Juan, et al. (1988). La conquista de Tenochtitlán, edición de Germán Vázquez. Madrid: Historia 16.

Díaz del CASTILLO, Bernal (2011 [1632]). Historia verdadera de la conquista de Nueva España, edición de Guillermo Serés. Madrid: Real Academia Española.

DuRÁN, fray Diego (1880). Historia de las Indias de Nueva España y islas de tierra firme. México: Ignacio Escalante.

EGío, José Luis (2016). «Acciones y virtudes políticas del Cortés de Gómara. Trascendencia secular de un juego de espejos». En: MARTíneZ MARTínEZ, María del Carmen y MAYER, Alicia (coords.). Miradas sobre Hernán Cortés. Madrid/Fráncfort: Iberoamericana/Vervuert, págs. 151-178.

FERNÁNDEZ DE OVIEDO, Gonzalo (1853 [1535]). Historia general y natural de las Indias, edición de Amador de los Ríos, tomo II. Madrid: Real Academia de la Historia.

GARCíA, Genaro (1901). Carácter de la conquista española en América y México, según los textos de los historiadores primitivos. Publicado por Cesáreo Fernández Duro en Boletín de la Real Academia de la Historia, tomo 39, págs. 399-411.

Graulich, Michel (1994). Montezuma. París: Fayard.

GrunBerg, Bernard (1995). Histoire de la conquête du Mexique. París: L'Harmattan. 
HASsIG, Ross (2012). «How fighting ended in the Aztec Empire and its surrender to the Europeans». En: Afflerbaugh, Holguer y Strachan, Hew. How fighting ends: A history of surrender. Oxford: Oxford University Press, págs. 114-124.

HASSIG, Ross (2016). «Timing and the conquest of Mexico». Estudios de Cultura Náhuatl, Ciudad de México, 51-I, págs. 173-196.

Herrera, Antonio de (1601). Historia general de los hechos de los castellanos en las islas y tierra firme del Mar Océano. Madrid: Juan Flamenco.

Josefo, Flavio (1891). Historia de la guerra de los judíos y de la destrucción del templo y ciudad de Jerusalén, traducción de Juan Martín Cordero. Madrid: Imprenta Viuda de Hernando y Cía., 2 vols.

LeÓn-Portilla, Miguel (1992). Visión de los vencidos. Madrid: Historia 16.

LEVY, Bernard (2010). Conquistador. Hernán Cortés, Moctezuma y la última batalla de los aztecas. Barcelona: Debate.

LÓPEZ DE GómARA, Francisco (2007 [1552]). Historia de la conquista de México. Caracas: Ayacucho.

LÓPEZ RAYÓn, Ignacio (1852-1853). Sumario de la residencia tomada a D. Fernando Cortés. México: Tipografía de Vicente Torres, 2 tomos.

Manzo Robledo, Francisco (2013). Yo, Hernán Cortés: el juicio de residencia. Madrid: Pliegos.

MartíneZ, José Luis (1992). Hernán Cortés. Madrid, Fondo de Cultura Económica / Universidad Nacional Autónoma de México.

Martínez Martínez, María del Carmen (2013). Veracruz 2013. Los hombres de Cortés. León: Consejo Nacional para la Cultura y las Artes - Instituto Nacional de Antropología e Historia / Universidad de León.

Martínez Martínez, María del Carmen y Mayer, Alicia (coords.) (2016). Miradas sobre Hernán Cortés. Madrid/Fráncfort: Iberoamericana/Vervuert.

Medin, Tzvi (2009). Mito, pragmatismo e imperialismo. La conciencia social en la conquista del Imperio azteca. Madrid/Fráncfort: Iberoamericana/Vervuert.

Mira Caballos, Esteban (2010). Hernán Cortés, el fin de una leyenda. Badajoz: Palacio de Barrantes Cervantes.

NavarRete, Federico (2011). «Chichimecas y toltecas en el valle de México». Estudios de Cultura Náhuatl, Ciudad de México, 42, págs. 19-50.

PIQUERAS, Ricardo (2002). «La transgresión en la conquista: violencia y canibalismo hispano». En: Dalla Corte Caballero, Gabriela (coord.). Conflicto y violencia en América. Barcelona: Universitat de Barcelona, págs. 41-51.

PIQUERAS, Ricardo (2006). "Los perros de la guerra o el "canibalismo canino" en la conquista». Boletín Americanista, Barcelona, 56, págs. 186-202.

PolavieJA, Camilo (1889). Hernán Cortés. Copias de documentos existentes en el archivo de Indias y en su palacio de Castilleja de la Cuesta sobre la conquista de México. Sevilla.

RuvalCaba MerCado, José (2018). «Los sacrificios humanos y su relación con la dieta y el canibalismo azteca en el momento de la Conquista». Revista Española de Antropología Americana, Madrid, 48, págs. 121-142.

SAHAGÚn, Bernardino de (1995 [1829]). Historia general de las cosas de Nueva España. Madrid: Alianza.

SAHAGún, Bernardino de (2001 [1829]). Historia general de las cosas de Nueva España, edición de Juan Carlos Temprano. Madrid: Dastin. 
Thomas, Hugh (1994). La conquista de México. Barcelona: Planeta.

THOMAS, Hugh (2001). Quién es quién de los conquistadores. Barcelona: Salvat.

TorquemadA, Juan de (1975-1983 [1615]). Monarquía indiana. México D. F.: Instituto de Investigaciones Históricas - Universidad Nacional Autónoma de México.

Fecha de recepción: 6 de noviembre de 2020

Fecha de aceptación: 25 de febrero de 2021

Fecha de publicación: 30 de junio de 2021 